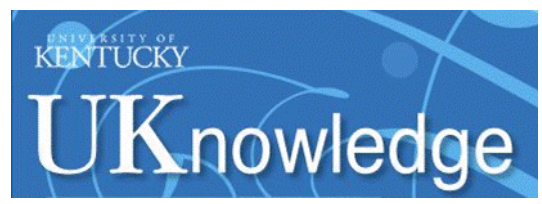

University of Kentucky

UKnowledge

$11-18-2016$

\title{
Hope, Aspirations, and Resilience in Children and Adolescents: A Review of Research on Measurement and Related Antecedents
}

\author{
Hildie Leung \\ The Hong Kong Polytechnic University, China \\ Florence K. Y. Wu \\ The Hong Kong Polytechnic University, China \\ Daniel T. L. Shek \\ University of Kentucky
}

Follow this and additional works at: https://uknowledge.uky.edu/pediatrics_facpub

Part of the Child Psychology Commons, and the Developmental Psychology Commons

Right click to open a feedback form in a new tab to let us know how this document benefits you.

\section{Repository Citation}

Leung, Hildie; Wu, Florence K. Y.; and Shek, Daniel T. L., "Hope, Aspirations, and Resilience in Children and Adolescents: A Review of Research on Measurement and Related Antecedents" (2016). Pediatrics Faculty Publications. 279.

https://uknowledge.uky.edu/pediatrics_facpub/279

This Article is brought to you for free and open access by the Pediatrics at UKnowledge. It has been accepted for inclusion in Pediatrics Faculty Publications by an authorized administrator of UKnowledge. For more information, please contact UKnowledge@lsv.uky.edu. 
Hope, Aspirations, and Resilience in Children and Adolescents: A Review of Research on Measurement and Related Antecedents

\section{Digital Object Identifier (DOI)}

https://doi.org/10.1515/ijdhd-2017-7003

Notes/Citation Information

Published in International Journal on Disability and Human Development, v. 16, issue 4, p. 351-358.

(C2017 Walter de Gruyter GmbH, Berlin/Boston.

The copyright holder has granted the permission for posting the article here. 
Hildie Leung, Florence K.Y. Wu and Daniel T.L. Shek*

\section{Hope, aspirations, and resilience in children and adolescents: a review of research on measurement and related antecedents}

DOI 10.1515/ijdhd-2017-7003

Received July 28, 2016; accepted September 1, 2016; previously published online November 18, 2016

\begin{abstract}
Hope, aspirations, and resilience are important developmental assets for children and adolescents. Based on the existing Western and Chinese literature, this review aims to identify instruments used to assess hope, aspirations, resilience, and conceptually related constructs as well as antecedents of the constructs in adolescents. A systematic literature search in the major databases was conducted. A total of 223 articles, with 144 being retrieved from international databases and 79 from China's database, met the criteria and were included in the present review. Findings revealed that the majority of the existing scales were developed predominantly in the West and there were few validated Chinese hope and aspirations scales. Indigenous measures were also not identified in the literature. In terms of antecedent studies, predictors at different levels including the personal, family, school, and community were found. Implications on the development of hope-based interventions and recommendations for future research are discussed.
\end{abstract}

Keywords: adolescents; aspirations; children; hope; instruments; resilience.

\footnotetext{
*Corresponding author: Daniel T.L. Shek, Chair Professor of Applied Social Sciences, Faculty of Health and Social Sciences, Department of Applied Social Sciences, The Hong Kong Polytechnic University, Room HJ407, Core H, Hunghom, Hong Kong, P.R. China, E-mail: daniel.shek@polyu.edu.hk; Centre for Innovative Programmes for Adolescents and Families, The Hong Kong Polytechnic University, Hong Kong, P.R. China; Kiang Wu Nursing College of Macau, Macau, P.R. China; Department of Social Work, East China Normal University, P.R. China; and Division of Adolescent Medicine, Department of Pediatrics, Kentucky Children's Hospital, University of Kentucky College of Medicine, Lexington, Kentucky, USA

Hildie Leung and Florence K.Y. Wu: Department of Applied Social Sciences, The Hong Kong Polytechnic University, Hong Kong, P.R. China
}

\section{Introduction}

Psychologists have long been preoccupied with human pathology prior to the dawn of the positive psychology movement. In 1998, Seligman argued that instead of merely focusing on studying what went wrong with individuals, a paradigm shift should be made to investigate what is non-pathological. Based on this premise, he established the field of positive psychology as the scientific study of factors that enable individuals to thrive, lead fulfilling lives, and achieve optimal human functioning [1]. In the area of developmental psychology, scholars shared the same sentiments and articulated the benefits of adopting a positive youth development approach to study and promote developmental assets among youngsters [2].

Among the developmental constructs, beliefs in the future (future aspirations, future orientations), hope, and resilience have been identified as important personal strengths for positive youth development [3, 4]. Beliefs in the future are defined as an internalization of hope and optimism about possible outcomes [5]. More specifically, hope is defined as "the process of thinking about one's goals, along with the motivation to move toward (agency) and the ways to achieve (pathways) those goals" [6]. According to Sun and Shek [4], "promotion of beliefs in the future for positive youth development deserves greater attention... noting that hope and optimism are two core components of beliefs in the future, it is necessary to help adolescents to internalize both hope and optimism" [4]. However, before this can be done, there is a need to examine (1) the theoretical concepts of hope, aspirations, and resilience; (2) how the concepts are measured among youth; (3) its antecedents; and (4) outcomes. The conceptual review of the concepts along with findings from outcome studies have been reported elsewhere. The present review attempted to identify instruments used to assess children and adolescent hope, aspirations, resilience, and conceptually related constructs as well as the antecedents of the constructs in the existing literature. It is hoped that this systematic review will allow for critical appraisal of existing studies and guide future research and hope-based interventions. 


\section{Method}

Studies published in journals spanning from 1980 to 2015 were included in the review. Articles were identified via online databases, including PsycINFO, Academic Search Premier, Web of Science, EBSCOhost database, and China's database CAJ Full-text Database. The search terms "dreams", "hope”, "aspirations", "future orientation", "resilience", "beliefs in the future", "children", and "adolescents" were used. Articles which met the following inclusion criteria were included in the review: (1) the focus of the study is the youth population, i.e. individuals aged between 6 and 18 years; (2) the study addressed the conceptualization of hope, aspirations, resilience, or its related concepts; (3) the study examines the development or validation of measurement tools of hope, aspirations, resilience, or its related concepts; and (4) the study was conducted in the Western context or in China. A total of 223 articles, with 144 being retrieved from international databases and 79 from the China's database met the criteria and were included in the present review.

\section{Measuring hope, aspirations, resilience and related concepts}

Several measurements on hope were identified in the literature review. In the West, commonly used instruments included the Adult Dispositional Hope Scale [7], Children's Hope Scale [8], Beck Hopelessness Scale [9], Hopelessness Scale for Children [10], and Herth Hope Index [11]. In China, the Chinese versions of the Adult Dispositional Hope Scale and Children's Hope Scale are the most widely administered instruments. Several observations were generated regarding the identified instruments. First, in terms of the target population, scales such as Herth Hope Index were initially developed for physically ill patients. As such, its generalizability to the general adolescent population may be limited. Second, some of the measures lack assessment of goal-setting and goal-pursuit which is particularly relevant to hope-based interventions that aim to enhance students' motivations to pursue their dreams [12]. Thus, there may be a need to include and adapt items from scales such as the Miller Hope Scale [13] and the Adult Dispositional Hope Scale [7], which assess goal identification and achievement. Third, the strengths of commonly used scales such as the Adult Dispositional Hope Scale and the Children's Hope Scale are that they have been validated in a Chinese context.

\section{Assessment of aspirations}

In terms of assessing aspirations among children and adolescents, studies revealed that the concept is measured in terms of two main dimensions, i.e. educational aspirations and career aspirations. For educational aspirations, most scholars (e.g. [14-16]) used a singleitem to assess students' educational aspirations by inviting them to indicate by a certain age (e.g. 30 years old), "What level of education do you hope to hold?" with options such as 0 (no further education planned), 9 (PhD or equivalent), to $10(M D, L L B, J D, D D S$, or equivalent). Some scholars also used other related items or scales to shed light on adolescents' academic aspirations such as their attitudes in school [17], or the amount of time they spend on their assignments or studies [18]. Given that there are few validated scales to measure educational aspirations in both Western and Chinese literature, there is a need to develop and validate scales to measure youth's educational aspirations, which include related concepts such as educational motivation, beliefs, self-efficacy, and associated behaviors.

Similar to the measurement of future orientation, there are few validated studies on career aspirations measurement. A commonly used instrument is the Career Aspirations Scale (CAS) [19], which includes three subscales (Leadership and Achievement, Job Satisfaction, and Continue Education). Other scholars assessed occupational aspirations of students by asking young people to indicate their preferred occupations using a single item such as "Nearly everyone of your age has some sort of idea of what they will want to do in life. Here is a list of the types of jobs/careers/professions for which various amounts of training are necessary. How about your choice(s)?" Researchers then categorized the data based on their research question (e.g. professional or managerial occupations vs. skilled, semiskilled, or unskilled jobs) (e.g. [20]).

In addition to the widespread categorization of career and educational aspirations, Kasser and Ryan [21] developed the Aspirations Index to assess both intrinsic (e.g. personal growth, relatedness, community service, and intellectual-aesthetic growth) and extrinsic (e.g. financial success, attractiveness, fame, power, and health) aspirations or life-goals. For studies conducted in mainland China, students' vocational aspirations were assessed using The Occupations List - Chinese Version (OLC) [22] based on Holland's Vocational Preference Inventory [23, 24]. While instruments measuring students' interests provide useful information, it is argued that "expressed interest in a profession has been shown to be equal to or to exceed interest inventories in predicting a person's future occupation" ([20], p. 212). Therefore, future studies may include both interest and expressed interest items to better understand youth's career aspirations. In addition, it may also be useful to measure students' difficulties in career decision-making with scales such as the Career Decision-making Difficulties Questionnaire [25], which will shed light on what to include in interventions to cater to the youth's needs.

\section{Assessment of future orientation}

Compared to other concepts in the present literature review (e.g. hope and resilience) there were relatively fewer scales measuring future orientation. Many scholars merely used a few items to measure future orientation such as "I have plans for my future", or "I am doing things now that will help me in the future" [26]. Two commonly used scales are Nurmi et al.'s [27] and Seginer et al.'s [28] Future Orientation Questionnaire which focuses on three future orientation domains (i.e. higher education, career, and marriage). Seginer and colleagues' scale provides a comprehensive assessment as it taps behavioral, cognitive, and motivational components of future orientation. Furthermore, the Life Orientation Test [29] was also used for children and adolescents. Sun and Shek [4] reported that the psychometrically validated Hope Scale [7] and the Life Orientation Test have been found to have convergent validity, which lends support to the interrelatedness of the concepts of hope, optimism, and future orientation.

Another commonly used measurement of future orientation is the Future Orientation Questionnaire [30] with open-ended questions where students were invited to list their hoped-for and feared 
selves. The interviewers then invited respondents to state the age they thought they could achieve their hoped-for selves, and also the extent they believed they could achieve their hoped-for selves (see [31]). In fact, many of the studies used a qualitative approach (e.g. interviews) to assess children's and adolescents' future orientation.

\section{Assessment of resilience}

Several observations can be drawn from the review. First, many resilience scales were initially developed for clinical practice as a measure of stress-coping ability among adults or adolescents who have experienced traumatic events, rather than measuring the profiles of children and adolescents in general. Second, in terms of methodological concerns, some scales yielded relatively low Cronbach's alpha values (e.g. Ego Resilience Scale) [32], which raises questions about the internal consistency of the items. Third, there is an absence of a psychometrically robust measure of resilience for young children. Fourth, few scales included items to assess the availability of assets and resources that facilitate resilience. Therefore, in order to gain a comprehensive picture of children's and adolescents' resilience, particularly if it were to shed light on intervention needs, the instrument should be able to assess a range of protective mechanisms across domains that contribute to resilience [33]. For instance, Donnon and Hammond's [34] Youth Resiliency: Assessing Developmental Strengths examines intrinsic and extrinsic protective factors among the youth.

\section{Predictors of hope, aspirations, and resilience among youth}

Developmental systems theory advocates the inherent plasticity of human development. That is, individuals have the potential for systematic change throughout their lifespan. These changes result from mutual interactions between the developing individual and his/her biological, psychological, as well as the ecological context (e.g. family, peers, school, community, and culture) [35]. Indeed, a review of literature on the development of aspirations and hope among children and adolescents revealed factors at different levels (i.e. individual, familial, school, and community) have impacts on the development of the different constructs.

\section{Individual factors}

On a personal level, gender and identity have been found to be predictors. Regarding the impact of gender on aspirations, existing findings in the West remain mixed. While some studies showed that female high school students were more future-oriented than their male counterparts on both career and education [36], other studies showed few gender differences in future orientation [37]. What is more interesting is that female and male adolescents had different career aspirations. Ashby and Schoon [38] found that a significantly higher proportion of teenage girls aspired to professional or managerial positions as compared with teenage boys. In terms of occupational dreams and aspirations, adolescent boys reported higher levels of entrepreneurial orientations [39]. Adolescent boys also preferred jobs in which they could be challenged. They aspired to have jobs in fields that are male-dominated (e.g. business management, architecture), whereas girls aspired to careers that are traditionally female-dominated (e.g. elementary school teaching, journalism) [40].

Gender differences were also observed in studies conducted in mainland China. In terms of resilience, studies conducted with Chinese migrant children [41] and university students [42] generally found that females reported higher levels of resilience. However, in a study of adolescents in Chengdu subsequent to the Sichuan earthquake, $\mathrm{Yu}$ and colleagues [43] found that male respondents reported higher resilience scores than did females. In Meng and colleagues' [44] study with primary and secondary school students who were affected by AIDS, boys reported higher levels of hope than did girls. In terms of future orientation, generally speaking, female students reported higher levels of future orientation than did male students [45]. More specifically, female students held higher levels of aspirations in the educational area, whereas males had higher aspirations in the marriage and family domain $[46,47]$.

In terms of career aspirations, using Holland's Vocational Preference Inventory [24], Hou and Leung [23] investigated vocational aspirations of Chinese high school students and identified gender differences, which suggested that male students aspired to occupational fields that were investigative, enterprising, and artistic (IEA) whereas female students aspired to artistic, enterprising, and investigative (AEI) occupations. Moreover, male students considered occupations of higher prestige and more masculinity compared with female students. Similarly, Creed et al. [48] found that Chinese male high school students aspired to investigative and enterprising types of occupations, but expected realistic and enterprising ones, whereas female students aspired to enterprising and conventional types, but expected conventional and social ones.

The above findings have important implications for interventions. First, to reconcile the discrepancy between aspirations and expectations, practitioners should focus 
on helping students to understand better possible career barriers and enhance their career-confidence to overcome those barriers. Second, students should be encouraged to expand their career interests. For instance, students should be encouraged to attend career exploration activities to increase their awareness of diverse career opportunities and different educational or career pathways to achieve their dreams. "The traditional Chinese idea that 'all trades and professions have their masters' could be useful as a 'culture-based' rationale to encourage openness to occupational alternatives" ([23], p. 358). Third, students should be encouraged to give more consideration to careers outside their gender stereotypes.

Besides gender, age has been identified as a factor affecting resilience. It is generally believed that adolescent resilience is a developmental process in which resilience increases with age. Children learn to make use of assets and resources when they are exposed to adversity. Their levels of resilience are enhanced when they successfully overcome low levels of risk, and become prepared to tackle greater challenges [49]. However, a literature search revealed that there are few studies conducted to specifically examine age differences in the development of hope and aspirations. Steinberg et al. [50] found that younger adolescents had lower levels of future orientation than individuals aged 16 years or over. Yet future orientation is a critical issue when children approach adolescence, because they are required to reflect and make detailed plans and realistic evaluations of their ability to reach future goals [51]. Scholars have therefore advised that interventions may begin in early high school years to encourage young adolescents to explore their future aspirations [23].

Besides gender and age, self-efficacy is also a personal predictor of future orientation. Self-efficacy in the context of future orientation refers to adolescents' internal beliefs about his/her level of competence and ability to perform well in the future [52]. According to studies conducted in the West and China, findings showed a consistent positive relationship between children's and adolescents' self-efficacy and their future orientation. Adolescents with higher levels of self-efficacy reported higher levels of educational aspirations (e.g. [53, 54]). In a study of adolescent vocational students in China, Zong and Li [55] found that students' career decision-making self-efficacy was positively correlated with characteristics of hope such as their way of thinking, will power, and general self-esteem. Indeed, the more efficacious students feel, the more likely they are able to persist in their studies and strive to attain their goals. Bandura et al. [56] also found that children's perceived efficacy influenced their career pursuits. Generally speaking, research findings supported that children's and adolescents' self-efficacy beliefs determine their career aspirations or options that they will consider. As such, interventions may aim to enhance children's and adolescents' self-efficacy. This can be done by (1) providing environments and opportunities that reinforce the probability that the child would experience success due to their own abilities and efforts; (2) empowerment through reinforcing their personal control to increase a sense of ownership and responsibility for their lives; (3) helping children and adolescents to identify their strengths and areas of competence which may be sources for pride and accomplishments; and (4) providing students with chances to showcase their talents and have them valued by significant figures (e.g. peers, parents, teachers) [57].

\section{Family factors}

In terms of socioeconomic status (SES), studies generally showed that well-off adolescents reported higher levels of aspirations compared with their counterparts from low-SES backgrounds [16]. Adolescents from higherincome families also aspired to more professional jobs and expected to stay in school than those from lowerincome families. Particularly, teenage girls from higherincome families were more likely to value having a job that enabled them to have higher levels of ambition and "aim high" [38]. An interesting finding in a recent Australian study showed that adolescents from high SES backgrounds cited interest and passion as motivation for their career choices, whereas their counterparts from low SES cited money as a consideration [58]. However, it is noteworthy that the pattern of SES on aspirations is different in studies conducted in China. Jiang [59] found that poorer college students reported higher levels of aspirations than did non-poor students. The author reasoned that this may be due to the increasing Government support allocated to alleviate their financial difficulties, which helped to enhance their self-esteem and motivation to achieve their goals.

Research has also showed that better family-functioning was related to higher levels of aspirations and hope among children and adolescents. For instance, supportive and safe parental relationships such as being able to seek help from and to freely communicate with parents helped the youth to maintain their future aspirations [3]. Adolescents with supportive parents were more optimistic and hopeful as well [60]. Children who perceived their parents as loving and supportive were more willing to develop a trusting and positive attitude towards their future, had 
more confidence in future success as a result of their contributions, and were more likely to invest to achieve their future goals [61]. However, Chinese American adolescents from families with more intergenerational conflicts reported higher levels of career indecision [62]. In China, a study conducted on migrant children also found that parent-child attachment was positively related to children's resilience [41]. Zhang and Zhang [46] also found that parent-child communication significantly predicted youth's career achievement planning.

Parenting is also an important determinant of hope and related constructs in adolescents. Scholars found that adolescents' perceived autonomous-accepting parenting was positively associated with their future orientation (e.g. [37, 63]). Adolescents who perceived their parents as warm and accepting reported higher levels of future orientation [52, 61]. In Nurmi and Pulliainen's [63] qualitative study, the authors found that among 11-year-olds, those who reported higher parental control were less optimistic about their future. However, for 15-year-olds, the higher the level of family discussion they reported, the more optimistic they were about their future. Indeed, it is believed that older adolescents may be more able to articulate their ideas and express their emotions related to future orientation, such as fear or hope [64]. Few studies have been conducted to examine the direct relationship between parenting and adolescents' future orientation in China. However, in a cross-cultural study comparing young adolescents from the USA, Canada, and China, Lekes and colleagues [65] found that universally, autonomy-supportive parents were more likely to endorse adolescents' intrinsic life goals (e.g. community-related goals such as improving the world, affiliation, self-acceptance), which was in turn associated with adolescent well-being and likely to impact on their future orientation. Wu and Chen [66] also found that parenting impacted on adolescents' resilience. Particularly, maternal emotional warmth significantly predicted college students' resilience, and paternal over protection had negative effects on resilience.

Parental expectations have also been shown to have a positive relationship with educational aspirations [67]. Ashby and Schoon [38] found that teenage career aspirations, ambition value, and educational performance at age 16 all increased with parental educational aspirations of their offspring. It is speculated that parents who have high expectations and aspirations for their children may be more involved in their studies and prioritized educational endeavors. Moreover, they may be more open and willing to discuss and communicate about their child's future. In China, Hou and Leung [23] found that parents expected male students to pursue investigative (e.g. science-related) occupations, whereas enterprising (e.g. business-related) occupations were preferred for both sons and daughters. Chinese parents often expect their children to work in scientific and professional fields and place a high value on prestige in job selection, especially for their sons [68]. These expectations are likely to impact on students' future career aspirations.

In addition, as Confucian values on family obligations are strong in the Mainland, individuals are expected to provide support, assistance, and respect to family members. Fuligni and Zhang [69] found that Chinese adolescents reported a strong sense of family obligation, and this was associated with higher levels of academic motivation. However, counter intuitively, family obligation was not associated with students' educational aspirations.

Given the importance of parental expectations and aspirations on the development of children's and adolescents' aspirations, some recommendations are suggested: (1) interventions may be designed to educate parents on "reasonable" and "realistic" parental expectations; (2) counselors and teachers may include parental participation in career exploration events; and (3) assistance should be given to students who experience internal conflicts, anxieties, or tensions between self-actualization and fulfilling family obligations. Students may be equipped with negotiation, conflict resolution, cooperation, assertiveness, and communication skills so that parents may recognize students' aspirations without feeling that they are disrespected or disobeyed [70].

\section{School factors}

Research showed that high-achieving adolescents reported higher future aspirations [16]. Plausible reasons are that high-achieving students have better self-concept and higher levels of self-efficacy, which has been found to have a positive impact on future orientation. Some scholars argued that a comparative effect of academic achievement may be present in school, where students compare their own academic performance to that of their peers. Students who have lower academic achievements may have a pessimistic future orientation and establish lower aspirations due to a sense of hopelessness and incompetence [71]. Furthermore, the authors found that a school climate of future orientation amplified the protective effects of adolescents' future orientation on problem behaviors.

Besides, adolescents who reported being more connected to their schools reported higher levels of future orientation. These students often have better academic 
performances and have high-quality relationships with their teachers and peers. It is reasoned that when adolescents feel more competent at school, they are more ready, willing, and confident to think and plan for their future [72]. Interventions may target at enhancing students' sense of belonging in the school context and encourage supportive peer relationships and student-teacher relationships.

\section{Community factors}

Strayhorn [16] found support for neighborhood effects on Black adolescents' educational aspirations where suburban adolescents reported higher levels of educational aspiration than did rural subjects. In fact, adolescents' achievement and aspirations have been shown to be correlated with the educational histories and aspirations of their peers [73]. It is argued that values and beliefs may be reinforced among peers in a neighborhood or system. Therefore, to maximize the positive neighborhood effect, it is recommended that resources may be devoted to establishing learning communities. For instance, afterschool programs may be developed to help students better prepare for university or tutoring classes may be arranged for low-achieving students especially in less resourceful communities.

\section{Conclusions}

Based on a comprehensive literature review on the existing measurements and antecedent studies of hope, aspirations, resilience, and related concepts on children and adolescents, the following observations and recommendations were put forth. In terms of scale development, there are few validated scales measuring future orientation and aspirations, especially in mainland China. Among the validated scales, such as resilience and hope measures, majority of them were developed by scholars in the West. Therefore, if studies were to be conducted on children and adolescents in the Mainland, indigenous measures that are cultural-specific should be developed or adapted with reference to the Chinese cultural characteristics (e.g. emphasis on family and relationships). Regarding findings from studies on the antecedents, factors on the personal, family, school, and community levels that may impact on children's and adolescents' development of resilience, hope, and aspirations in both the Western and Chinese contexts have been identified. It is recommended that efforts to promote the development of hope and aspirations should take into consideration the risk and protective factors at each level and adopt a holistic approach to address them.

While the review provides integrative coverage of existing literature in the area of youth hope and aspirations from both the Western and Chinese contexts, a limitation is that only published journal articles were included in the review. Unpublished research such as dissertations, book chapters, and conference papers was excluded. However, given that the aim of the present review is to provide a comprehensive picture of where current research stands, particularly those positioned to influence knowledge development as well as instruments used in the existing literature. Thus, we believe that only rigorous studies that have been published in peer-reviewed journals should be included. As the field develops, a more complete review may include unpublished studies as well as findings from other Asian contexts.

Acknowledgments: This research was financially supported by The Bao Bao Bear Care Foundation Limited. The materials in this paper are based on the unpublished report entitled "Literature Review on Hope and Aspirations in Children and Adolescents" submitted to the Foundation.

\section{References}

1. Seligman ME, Csikszentmihalyi M. Special issue on happiness, excellence, and optimal human functioning. Am Psychol 2000;55:5-183.

2. Catalano RF, Hawkins JD, Berglund ML, Pollard JA, Arthur MW. Prevention science and positive youth development: competitive or cooperative frameworks? J Adolesc Health 2002;31:230-9.

3. McCoy H, Bowen EA. Hope in the social environment: factors affecting future aspirations and school self-efficacy for youth in urban environments. Child Adolesc Soc Work J 2015;32:131-41.

4. Sun RC, Shek DT. Beliefs in the future as a positive youth development construct: A conceptual review. ScientificWorldJournal 2012. Article ID 527038, 8 pages. doi:10.1100/2012/527038.

5. Catalano RF, Berglund ML, Ryans JA, Lonczak HS, Hawkins JD. Positive youth development in the United States: research findings on evaluations of positive youth development programs. Washington, DC: Office of Assistant Secretary for Planning and Evaluation, 1998. URL: http://www.aspe.hhs.gov/hsp/ PositiveYouthDev99/.

6. Snyder CR. Conceptualizing, measuring, and nurturing hope. J Couns Dev 1995;73:355-60.

7. Snyder CR, Harris C, Anderson JR, Holleran SA, Irving LM, Sigmon ST, et al. The will and the ways: development and validation of an individual-differences measure of hope. J Pers Soc Psychol 1991;60:570-85. 
8. Snyder CR, Hoza B, Pelham WE, Rapoff M, Ware L, Danovsky M, et al. The development and validation of the Children's Hope Scale. J Pediatr Psychol 1997; 22:399-421.

9. Beck AT, Steer RA. Beck Hopelessness Scale manual. San Antonio, TX: Psychological corporation, 1988.

10. Kazdin AE, Rodgers A, Colbus D. The hopelessness scale for children: psychometric characteristics and concurrent validity. J Consult Clin Psych 1986;54:241-5.

11. Herth K. Development and refinement of an instrument to measure hope. Sch Inq Nurs Pract 2001;5:39-51.

12. Schrank B, Bird V, Rudnick A, Slade M. Determinants, self-management strategies and interventions for hope in people with mental disorders: systematic search and narrative review. Soc Sci Med 2012;74:554-64.

13. Miller JF, Powers MJ. Development of an instrument to measure hope. Nurs Res 1988;37:6-10.

14. Carranza FD, You S, Chhuon V, Hudley C. Mexican American adolescents' academic achievement and aspirations: The role of perceived parental educational involvement, acculturation, and self-esteem. Adolescence 2009;44:313-33.

15. Carter DF. A dream deferred?: Examining the degree aspirations of African American and White college students. New York: Taylor Francis, 2001.

16. Strayhorn TL. Different folks, different hopes: the educational aspirations of black males in urban, suburban, and rural high schools. Urban Educ 2009;44:710-31.

17. McCoach DB. The school attitude assessment survey-revised. Unpublished instrument, 2000.

18. Huang SY. Learning environments at higher education institutions: relationships with academic aspirations and satisfaction. Learn Environ Res 2012;15:363-78.

19. O’Brien KM. Career aspiration scale. College Park, MD: Department of Psychology, University of Maryland, 1992.

20. Schoon I, Polek E. Teenage career aspirations and adult career attainment: the role of gender, social background and general cognitive ability. Int J Behav Dev 2011;35:210-7.

21. Kasser T, Ryan RM. Further examining the American dream: differential correlates of intrinsic and extrinsic goals. Pers Soc Psychol B 1996;22:280-7.

22. Leung SA, Harmon LW. Individual and sex differences in the zone of acceptable alternatives. J Couns Psychol 1990;37:153.

23. Hou ZJ, Leung SA. Vocational aspirations of Chinese high school students and their parents' expectations. J Vocat Behav 2011;79:349-60.

24. Holland JL. Manual for the vocational preference inventory. Odessa, FL: Psychological Assessment Resources, 1985.

25. Gati I, Saka N. High school students' career-related decisionmaking difficulties. J Couns Dev 2001;79:331-40.

26. Peters RJ, Tortolero SR, Johnson RJ, Addy RC, Markham CM, Escobar-Chaves SL, et al. The relationship between future orientation and street substance use among Texas alternative school students. Am J Addict 2005;14:478-85.

27. Nurmi JE, Seginer R, Poole M. Future-orientation questionnaire. Helsinki, Finland: Department of Psychology, University of Helsinki, 1990.

28. Seginer R, Shoyer S, Hossessi R, Tannous H. Adolescent family and peer relationships: does culture matter? New Dir Child Adolesc Dev 2007;116:83-99.
29. Scheier MF, Carver CS. Optimism, coping, and health: assessment and implications of generalized outcome expectancies. Health Psychol 1985;4:219-47.

30. Trommsdorff G, Lamm H, Schmidt RW. A longitudinal study of adolescents' future orientation (time perspective). J Youth Adolesc 1979;8:131-47.

31. Yowell CM. Possible selves and future orientation: exploring hopes and fears of Latino boys and girls. J Early Adolesc 2000;20:245-80.

32. Bromley E, Johnson JG, Cohen P. Personality strengths in adolescence and decreased risk of developing mental health problems in early adulthood. Compr Psychiatry 2006;47:315-24.

33. Windle G, Bennett KM, Noyes J. A methodological review of resilience measurement scales. Health Qual Life Outcomes 2011;9:1-18.

34. Donnon T, Hammond W. Understanding the relationship between resiliency and bullying in adolescence: an assessment of youth resiliency from five urban junior high schools. Child Adolesc Psychiatr Clin North Am 2007;16:449-71.

35. Lerner RM, Lerner JV, Almerigi JB, Theokas C, Phelps E, Gestsdottir S, et al. Positive youth development, participation in community youth development programs, and community contributions of fifth-grade adolescents findings from the first wave of the 4-H study of positive youth development. J Early Adolesc 2005;25:17-71.

36. Kolesovs A. Domain-specific and general future orientation of high school students in Latvia under socioeconomic changes. Int J Psychol: Biopsychosoc App 2013;12:71-83.

37. Seginer R, Vermulst A, Shoyer S. The indirect link between perceived parenting and adolescent future orientation: a multiple-step model. Int J Behav Dev 2004;28:365-78.

38. Ashby JS, Schoon I. Career success: The role of teenage career aspirations, ambition value and gender in predicting adult social status and earnings. J Vocat Behav 2010;77:350-60.

39. Schmitt-Rodermund E, Vondracek FW. Occupational dreams, choices and aspirations: adolescents' enterpreneurial prospects and orientations. J Adolesc 2002;25:65-78.

40. Nikolayenko O. Adolescents' hopes for personal, local, and global future: insights from Ukraine. Youth Soc 2011;43:64-89.

41. Mao XJ, Wang ZH. Migrant children's attachment to their parents and its effect on their resilience. Chinese J Spec Educ 2013;153:50-5.

42. Han L, Liao CJ, Zheng Y. Status of spiritual belief and psychological resilience and their correlation among university students. Chinese J Pub Health 2014;30:275-8.

43. Yu XN, Lau JT, Mak WW, Zhang J, Lui WW. Factor structure and psychometric properties of the Connor-Davidson Resilience Scale among Chinese adolescents. Compre Psychiatry 2011;52:218-24.

44. Meng QF, Zhong YH, Tian YH. Relationship of subjective wellbeing and belief in a just world and hope of AIDS-affected children. Chinese Ment Health J 2015;29:28-33.

45. Wang $\mathrm{Q}$. The relationship between future orientation and self-esteem among college students. J Neijiang Normal U 2014;29:43-7.

46. Zhang LL, Zhang WX. Personal future planning in middle and late adolescence and its relation to adolescents' communication with parents and friend. Acta Psychol Sinica 2008;40:583-92. 
47. Zhang WX, Xu FZ, Zhang LL, Wang SQ, Yu FJ, Gao T. The relationships of Chinese college students' personal future planning and attitude towards future with depression. Psychol Sci 2009;32:824-7.

48. Creed PA, Wong OY, Hood M. Career decision-making, career barriers and occupational aspirations in Chinese adolescents. Int J Educ Vocat Guid 2009;9:189-203.

49. Yates TM, Egeland B, Sroufe A. Rethinking resilience. In: Luthar $S$, editor. Resilience and vulnerability: adaptation in the context of childhood adversity. Cambridge: Cambridge University Press, 2003:243-66.

50. Steinberg L, Graham S, O’Brien L, Woolard J, Cauffman E, Banich $M$. Age differences in future orientation and delay discounting. Child Dev 2009;80:28-44.

51. Gao S, Chan EK. Future orientation and school bullying among adolescents in rural China: the mediating role of school bonding. Sage Open 2015;5:1-9.

52. Nurmi JE. Age, sex, social class, and quality of family interaction as determinants of adolescents' future orientation: a developmental task interpretation. Adolescence 1987;22:977-91.

53. Kerpelman JL, Mosher LS. Rural African American adolescents' future orientation: the importance of self-efficacy, control and responsibility, and identity development. Identity: Int J Theor Res 2004;4:187-208.

54. Kerpelman JL, Eryigit S, Stephens CJ. African American adolescents' future education orientation: associations with self-efficacy, ethnic identity, and perceived parental support. J Youth Adolesc 2008;37:997-1008.

55. Zong JS, Li XP. Relationship between vocational students' characteristics of hope, self-esteem and career decision-making self-efficacy. J Southwest Jiaotong U 2014;15:84-8.

56. Bandura A. Self-efficacy mechanism in human agency. Am Psychol 1982;37:122.

57. Brooks RB. Children at risk: Fostering resilience and hope. Am J Orthopsychiatry 1994; 64:545-53.

58. Gore J, Holmes K, Smith M, Southgate E, Albright J. Socioeconomic status and the career aspirations of Australian school students: testing enduring assumptions. Aust Educ Res 2015;42:155-77.

59. Jiang YJ. The status quo and features of poor college students' level of aspiration. J Henan Univ (Soc Sci) 2011;51:139-43.
60. Neblett NG, Cortina KS. Adolescents' thoughts about parents' jobs and their importance for adolescents' future orientation. J Adolesc 2006;29:795-811.

61. Trommsdorff G. Future orientation and socialization. Int J Psychol 1983;18:381-406.

62. Ni H, Li C, Zhao J. Cultural consideration of resilience for Chinese immigrant children and adolescents. North Am J Med Sci (Boston) 2014;7:112-6.

63. Nurmi JE, Pulliainen H. The changing parent-child relationship, self-esteem, and intelligence as determinants of orientation to the future during early adolescence. J Adolesc 1991;14:35-51.

64. Nurmi JE. How do adolescents see their future? A review of the development of future orientation and planning. Dev Rev 1991;11:1-59.

65. Lekes N, Gingras I, Philippe FL, Koestner R, Fang J. Parental autonomy-support, intrinsic life goals, and well-being among adolescents in China and North America. J Youth Adolesc 2010;39:858-69.

66. Wu WC, Chen DF. Research on the relationship between parenting style and college students' resilience. J Shaoguan U 2014;35:155-8.

67. Benner AD, Mistry RS. Congruence of mother and teacher educational expectations and low-income youth's academic competence. J Educ Psychol 2007;99:140-53.

68. Leong FT, Serafica FC. Career development of Asian Americans: a research area in need of a good theory. In: Leong FT, editor. Career development and vocational behavior of racial and ethnic minorities. New York: Lawrence Erlbaum, 1995:67-102.

69. Fuligni AJ, Zhang W. Attitudes toward family obligation among adolescents in contemporary urban and rural China. Child Dev 2004;75:180-92.

70. Leung SA, Chen PH. Counseling psychology in Chinese communities in Asia indigenous, multicultural, and cross-cultural considerations. Couns Psychol 2009;37:944-66.

71. Chen P, Vazsonyi AT. Future orientation, school contexts, and problem behaviors: a multilevel study. J Youth Adolesc 2013;42:67-81.

72. Crespo C, Jose PE, Kielpikowski M, Pryor J. "On solid ground”: family and school connectedness promotes adolescents' future orientation. J Adolesc 2013;36:993-1002.

73. Coleman JC. The parenting of adolescents in Britain today. Child Soc 1997;11:44-52. 